\title{
Assessing Knowledge of the Effects of Obesity/Overweight in staff of a Non-Governmental Organization in AkwaIbom State Nigeria
}

\author{
Article by Angela Chinyelu Momoh \\ MPH Student Texila American University, Nigeria \\ Email: angela.momoh@texilaconnect.com
}

\begin{abstract}
Prolonged sitting and sedentary behavior comprises a major part of the modern lifestyle: at work, leisure (watching television, Internet) and commuting/traveling, and this has been implicated in the prevalence of overweight and obesity. The study sought to assess the degree of knowledge of a population of non-governmental staff in AkwaIbom state Nigeria on the health effects of overweight and obesity. A questionnaire was administered through direct interview to fifty (n-50) staff in FHI360 AkwaIbom state office, Nigeria who gave verbal consent (Non-Health Personnel ( $n=23)$, Laboratory Personnel $(n=8)$, Doctor $(n=15)$, and Pharmacist $(n=4) .82 \%$ of respondents have an appreciable knowledge of the health effects of overweight/obesity, 95.5\% the causes, while $74.5 \%$ are aware that BMI (body Mass Index) can be used as a monitoring tool for overweight/obesity, however, only a total $42.8 \%$ of respondents knew their BMI. There is therefore an urgent need to create an avenue in form of health fare for the study population to determine their BMI and improve their lifestyle/health seeking behavior to avoid the adverse health effects of overweight/obesity.
\end{abstract}

\section{Background}

The epidemiological transition of Chronic non-communicable diseases in sub-Saharan Africa seems to have overtaken the infectious diseases that have been in the fore front, such as HIV/AIDS and tuberculosis (Reddy and Yusuf (1998), Omran(2001).), WHO defined Overweight and obesity, as body mass index $\geq 25 \mathrm{~kg} / \mathrm{m} 2$ and $\geq 30 \mathrm{~kg} / \mathrm{m} 2$, respectively, and are associated with several diseases including cardiovascular disease, diabetes and several types of cancer (Lim et. al, 2010). 1.4 billion Adults aged 20 years and above were overweight or obese in 2008, of whom approximately 200 million men and 300 million women were estimated to be obese (WHO, 2010). Projections by 2030, fore sees an estimate of 2.16 billion overweight and 1.12 billion obese individuals globally (Kelly et al, 2008), two or more billion people worldwide are currently overweight or obese derived from results of trend analysis (Popkin et al 2012). The global disease burden attributable to high body-mass index increased from 52 million in 1990 to 94 million disability-adjusted life-years in 2010 tuberculosis (Reddy and Yusuf (1998), Omran(2001).).According to the 2010 WHO survey data on Nigeria the prevalence of overweight was $26 \%$ and $37 \%$ in men and women respectively, while the prevalence of obesity was $3 \%$ and $8.1 \%$ in men and women respectively (Ono et al 2005:2012). Data from the WHO Global InfoBase on individuals aged 30 years and above (Akarolo-Anthonyet al, (2014), shows that the prevalence of overweight and obesity together increased by $23 \%$ in men and $18 \%$ in women, while the prevalence of obesity alone increased by $47 \%$ in men and $39 \%$ in women, between 2002 and 2010, in Nigeria (Ono et al 2005:2012). Prolonged sitting and sedentary behavior comprises a major part of the modern lifestyle: at work, leisure (watching television, Internet) and commuting/traveling, (Shiyovichet al 2013). Studies have shown that adults spend about half of their time at work and even more sitting (Shiyovichet al 2013). Similarly, a significant part of the leisure (Shiyovichet al 2013) time is spent doing sedentary activities usually in front of a screen (TV or a computer).Recent evidence from several research papers showed deleterious relationships of sedentary behavior with cardiovascular risk factors (e.g., obesity, type 2 diabetes mellitus and waist circumference(Shiyovichet al 2013)). Furthermore, consistent independent associations (Shiyovichet al 2013) have been observed between sitting time/sedentary 
South American Journal of Public Health

Special Edition May 2016

behaviors and elevated all-cause and cardiovascular disease mortality risk(Shiyovichet al 2013).

\section{Rationale of the study}

In FHI360 Akwalbom state, prolonged sitting (internet) and sedentary behavior, commuting/traveling comprises a major part of the work schedule and little or no study has been done to assess the knowledge of staff on the risk factors of overweight/obesity though they may be aware as they are mostly health personnel but it cannot be taken for granted that they monitor their BMI, it is on this premise that this study is being conducted.

\section{Objective}

- To Assess the degree of Knowledge of the Effects of Obesity/overweight in staff of a Non-Governmental Organization in Akwalbom State Nigeria

- $\quad \mathrm{T}$ o assess the degree of Knowledge of BMI(Body Mass Index)as a monitoring tool for Obesity/overweight in same population

- T o recommend based on the outcome of the study on possible ways to entrench health talks/healthy work habits in the same population.

\section{Methods}

This study was qualitative, and descriptive. A questionnaire was administered through direct interview to fifty (n-50) staff in FHI360 Akwalbom state office, Nigeria who gave verbal consent (Non- Health Personnel $(n=23)$, Laboratory Personnel $(n=8)$, Doctor $(n=15)$, and Pharmacist $(\mathrm{n}=4)$. The questionnaire sought to assess the degree of knowledge of Health effects and causes of overweight/obesity, Knowledge of Body Mass Index(BMI) as a monitoring tool for overweight /obesity and assessing knowledge of own BMI as a health seeking behavior and in the same vein assess lifestyle by nocturnal eating syndrome( eating in the middle of the night), Snack and Carbonated drinks consumption; degree of physical activity by watching a lot of Television after work and amount of physical exercise conducted daily. Qualitative categorical data was analyzed manually and described the data per study question and respondent group by job category.

\section{Results}

Table 1: Distribution by Job category of Respondents

\begin{tabular}{lllll} 
Job Category & Male & Female & n & \% \\
\hline Non Health Personnel & 12 & 11 & 23 & 46 \\
Laboratory Personnel & 5 & 3 & 8 & 16 \\
Doctor & 15 & 0 & 15 & 30 \\
Pharmacist & 3 & 1 & 4 & 8 \\
Total & $\mathbf{3 5}$ & $\mathbf{1 5}$ & $\mathbf{5 0}$ & $\mathbf{1 0 0}$ \\
\hline
\end{tabular}

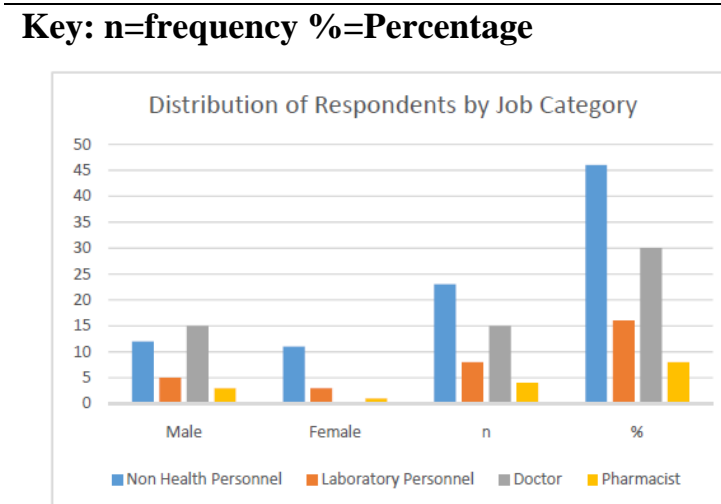


Table 2: Distribution of Respondents by their Knowledge of Overweight/Obesity

\begin{tabular}{|c|c|c|c|c|c|c|c|c|}
\hline \multirow{4}{*}{$\begin{array}{l}\text { Knowledge of Health } \\
\text { effects of Obesity } \\
\text { Knowledge of } \\
\text { Cause(s) of } \\
\text { Overweight/Obesity }\end{array}$} & \multicolumn{2}{|c|}{$\begin{array}{l}\text { Non-Health } \\
\text { Personnel }\end{array}$} & \multicolumn{2}{|c|}{$\begin{array}{l}\text { Laboratory } \\
\text { Personnel }\end{array}$} & \multicolumn{2}{|l|}{ Doctor } & \multicolumn{2}{|c|}{ Pharmacist } \\
\hline & $\begin{array}{l}\text { Yes } \\
\mathrm{n}(\%)\end{array}$ & $\begin{array}{l}\text { No } \\
\mathrm{n}(\%)\end{array}$ & $\begin{array}{l}\text { Yes } \\
\mathrm{n}(\%)\end{array}$ & $\begin{array}{l}\text { No } \\
\mathrm{n}(\%)\end{array}$ & $\begin{array}{l}\text { Yes } \\
\mathrm{n}(\%)\end{array}$ & $\begin{array}{l}\text { No } \\
\mathrm{n}(\%)\end{array}$ & $\begin{array}{l}\text { Yes } \\
\mathrm{n}(\%)\end{array}$ & $\begin{array}{l}\text { No } \\
\mathrm{n}(\%)\end{array}$ \\
\hline & $18(78)$ & $5(22)$ & $4(50)$ & $4(50)$ & $15(100)$ & $0(0)$ & $4(100)$ & $0(0)$ \\
\hline & $22(95)$ & $1(5)$ & $8(100)$ & $0(0)$ & $13(87)$ & 2(13) & $4(100)$ & $0(0)$ \\
\hline $\begin{array}{l}\text { Knowledge of BMI as } \\
\text { a monitoring tool for } \\
\text { Overweight/Obesity }\end{array}$ & $14(61)$ & $9(39)$ & $6(75)$ & $2(25)$ & $13(87)$ & 2(13) & $3(75)$ & $1(25)$ \\
\hline $\begin{array}{l}\text { Knowledge of own } \\
\text { BMI }\end{array}$ & $7(30)$ & $16(70)$ & $3(37)$ & $5(63)$ & 11(79) & $4(21)$ & $1(25)$ & $3(75)$ \\
\hline
\end{tabular}

Key: $\mathrm{n}=$ frequency BMI=Body Mass Index \%=Percentage

Table 3: Distribution of Respondents by Predisposing Factors to Overweight/Obesity

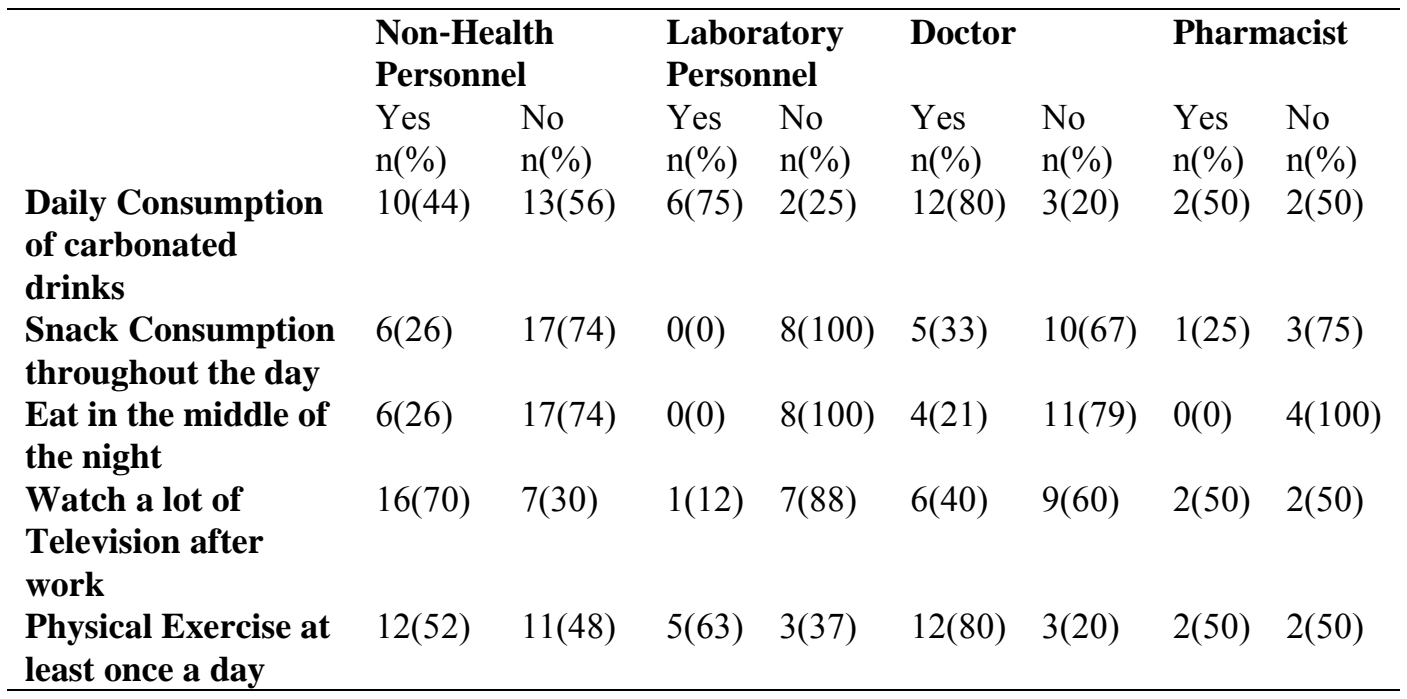

Key: $n=$ frequency $\%=$ Percentage

\section{Discussion}

The respondents in this study comprised of $\mathrm{N}=50$ : Non-Health Personnel (46\%), Laboratory Personnel (16\%), Doctor (30\%), and Pharmacist (8\%). (Table 1)

Based on Table 2, $82 \%$ of respondents have an appreciable knowledge of the health effects of overweight/obesity, $95.5 \%$ the causes, while $74.5 \%$ are aware that BMI (body Mass Index) can be used as a monitoring tool for overweight/obesity, however, only a total $42.8 \%$ of respondents knew their BMI( Doctors making up $79 \%$ of this total percentage). Which indicates poor health seeking behavior and lack of consciousness to the adverse health effects of overweight/obesity amongst staff or the overwhelming workload: though majority of respondents are non-health personnel. Further studies should seek to determine the BMI of same population to identify those needing lifestyle change to avoid the harmful effects of overweight/obesity.

Table 3, focused on the distribution of Respondents by Predisposing Factors to Overweight/Obesity. It was observed that $62.2 \%$ of respondents consume sugar sweetened/carbonated soft drinks daily, evidence from the Framingham study indicates that consumption of soft drinks has been linked with metabolic syndrome and cardiovascular risk, (Dhingra et al 2007); similarly, consumption of sugar sweetened beverages in the USA 
South American Journal of Public Health

Special Edition May 2016

contributes to positive energy balance and reducing consumption has beneficial effects on body weight, (Ebbeling 2014), and in the same vein, Soft drink consumption is significantly linked to overweight, obesity, and diabetes worldwide (Basu et al (201 3), including in lowand middle-income countries.( Sanjay et al, 2013)

$21 \%$ of respondents consume snacks throughout the day, and according to French et al (1994 and 2000),higher baseline consumption of fast food was associated with increased weight gain after 15 years, significantly increased insulin resistance in all ethnic/gender groups and some cross-sectional studies have shown similar associations between fast food intake and increased body weight.

$11.8 \%$ of respondents eat in the middle of the night, One behavioral study found that the food intake of night-eaters to be greater than that of non-night-eaters. (Allison et al (2005) $\&$ Boston et al (2008)), this will of course predispose this particular population to weight gain and eventually obesity. $43 \%$ of respondents watch a lot of television after work, while $61.2 \%$ carry out physical exercise at least once a day ranging from jogging, brisk walk and stair climbing; Both high levels of physical activity and low levels of leisure time sitting may be required to substantially reduce the risk of obesity, (Joshua et al 2014). Evidence also supports the contribution of both excess energy intake and decreased energy expenditure in the obesity epidemic. (Kant et al (2006), Prentice and Jebb(1995), Dietz and Gortmaker, (1985)).

\section{Conclusion}

The population under study have an appreciable knowledge of the effects, causes and the use of BMI as a monitoring tool of overweight/obesity however, half of the population has no knowledge of their BMI hence the need to create an avenue in form of health fare so that staff can determine their BMI and improve their lifestyle/health seeking behaviour to avoid the adverse health effects of overweight/obesity.

\section{References}

[1.] Akarolo-Anthony SN, Willett WC, Spiegelman D, and Adebamowo CA (2014). Obesity epidemic hasemerged among Nigerians.BMC Public Health, 14:455

http://www.biomedcentral.com/1471-2458/14/455

[2.] Allison KC, Ahima RS, O'Reardon JP, Dinges DF, Sharma V, Cummings DE, et al. (2005): Neuroendocrine profiles associated with energy intake, sleep, and stress in the night eating syndrome. $J$ Clin Endocrinol Metab.; 90:6214-6217.

[3.] Basu S, M cKee M, Galea G, Stuckler D. (201 3): Relationship of soft drink consumption to global overweight, obesity, and diabetes: a cross-national analysis of 75 countries. Am J Public Health $103\left(\begin{array}{lll}1 & 1\end{array}\right): 2071-7$

[4.] Dhingra R, Sullivan L, Jacques PF, et al (2007) . Soft drink consumption and risk of developing cardiometabolic risk factors and the metabolic syndrome in middle aged adults in the community. Circulation; 116:480-488

[5.] Dietz WH Jr, Gortmaker SL. (1985): Do we fatten our children at the television set? Obesity and television viewing in children and adolescents. Pediatrics; 75(5):807-812.

[6.] Ebbeling, Cara B.(2014) Sugar-sweetened beverages and body weight. Current Opinion in Lipidology: Volume 25 - Issue 1 - p 1-7

[7.] French SA, Jeffery RW, Forster JL, McGovern PG, Kelder SH, Baxter JE. (1994): Predictors of weight change over two years among a population of working adults: the Healthy Worker Project. Int $J$

Obes Relat Metab Disord.; 18:145-154. French SA, Harnack L, Jeffery RW. (2000): Fast food restaurant use among women in the Pound of Prevention study: dietary, behavioral and demographic correlates. Int J Obes Relat Metab Disord.;24:1353-1359

[8.] Joshua A. Bell \&Mark Hamer\&G. David Batty \&Archana Singh-Manoux\&Séverine Sabia \& Mika Kivimaki (2014): Combined effect of physical activity and leisure time sitting on long-term risk of incident obesity and metabolic risk factor clustering. Springerlink.com 
[9.] Kant AK, Graubard BI. (2006): Secular trends in patterns of self-reported food consumption of adult Americans: NHANES 1971-1975 to NHANES 1999-2002. Am J Clin Nutr 84(5): 1215-1223.

[10.] Kelly T, Yang W, Chen CS, Reynolds K, He J(2008): Global burden of obesity in 2005 and projections to 2030. Int J Obes, 32:1431-1437.

[11.] Lim SS, Vos T, Flaxman AD, Danaei G, Shibuya K, Adair-Rohani H, Amann M, Anderson HR, Andrews KG, Aryee M, Atkinson C, Bacchus LJ, Bahalim AN, Balakrishnan K, Balmes J, Barker-Collo S, Baxter A, Bell ML, Blore JD, Blyth F, Bonner C, Borges G, Bourne R, Boussinesq M, Brauer M, Brooks P, Bruce NG, Brunekreef B, Bryan-Hancock C, Bucello C, et al: A comparative risk assessment of burden of disease and injury attributable to 67 risk factors and risk factor clusters in 21 regions, 1990-2010: a systematic analysis for the Global Burden of Disease Study 2010. Lancet 2013, 380:2224-2260.

[12.] Omran A (2001). The epidemiologic transition. A theory of the Epidemiology of population change. Bull World Health Organ. 79(2):161-170.

[13.] Ono T, Guthold R, Strong K (2005; 2012: WHO Global Comparable Estimates: Global Infobasdata for saving lives. https://apps.who.int/infobase/Index.aspx.

[14.] Popkin BM, Adair LS, Ng SW (2012): Global nutrition transition and the pandemic of obesity in developing countries. Nutr Rev, 70:3-21.

[15.] Prentice AM, Jebb SA. (1995): Obesity in Britain: gluttony or sloth? BMJ 12; 311(7002):437439.

[16.] Reddy K and Yusuf S (1998). Emerging epidemic of cardiovascular disease in developing countries. Circulation. 97(6):596-601.

[17.] RC Boston, PJ Moate, KC Allison, JD Lundgren, Stunkard AJ.(2008): Modeling circadian rhythms of food intake by means of parametric deconvolution: results from studies of the night eating syndrome. Am J ClinNutr.; 87:1672-1677.

[18.] Shiyovich A1, Shlyakhover V, Katz A. (2013): Sitting and cardiovascular morbidity and mortality, Harefuah; 152(1):43-8, 58, 57.

[19.] Sanjay Basu, Martin McKee, Gauden Galea, and David Stuckler,(201 3) Relationship of Soft Drink Consumption to Global Overweight, Obesity, and Diabetes: A Cross-National Analysis of 75 Countries. American Journal of Public Health: Vol. 103, No. 11, pp. 2071-2077.

[20.] WHO: Fact sheet on Obesity 2010; 2012. http://www.who.int/topics/obesity/en/. 